\title{
Designing And Evaluating A Personal Skills Development Program For Management Education
}

Elvy Pang, Hong Kong Polytechnic University, China

Humphry Hung, Hong Kong Polytechnic University, China

\begin{abstract}
Success in preparing business students for professional careers requires these students to develop a set of well-defined personal skills. The present study examined 145 business students to assess the effectiveness of a personal skills development (PSD) program by measuring the impact of the training on the students' attitudes in skill development and by evaluating their satisfaction of the learning process. We present the planning and implementation processes of a comprehensive semester-long program in an English-speaking university in Asia that aims to develop the personal skills of business undergraduates. Differences between pre- and post-test perceived ability skill levels were highly significant $(p<.01)$. Respondents also agreed that the program has a positive impact on their skill development and reported satisfaction with the learning experience. This study provides suggestions to business educators on developing and evaluating a range of personal skills amongst students. Recommendations and limitations of the study are discussed.
\end{abstract}

Keywords: Personal Skills; Soft Skills; Skills-Based Learning; Students; Hong Kong

\section{INTRODUCTION}

iven today's fast-changing environment and increasing market competition, it is no longer sufficient for students in business schools to acquire academic knowledge only. They also need to possess a range of personal skills that prospective employers are looking for (Garavalia \& Gredler, 2004). However, studies have shown that the personal skills of today's graduates are poorer than their counterparts in previous generations (e.g. Bennett, 2002) and that a significant percentage (44.7\%) of employers finds it difficult to recruit graduates with appropriate skills (Nabi \& Bagley, 1999). Research finds that even graduates from leading business schools lack the personal skills that organizations need (Bennis \& O’Toole, 2005).

Despite the fact that there have been efforts to enhance curricula for business education programs, educators and researchers continue to be critical of their failure to sufficiently prepare students for organizational success (Gammie, Gammie \& Cargill, 2002). One of the possible causes of this problem is a lack of effective tools to develop and evaluate skills development programs. The primary obstacles include problems in defining objective and outcome variables that will yield useful evaluation results and difficulties establishing comparative benchmarks against which program outcomes should be gauged (Flannery \& Pragman, 2010; Garavalia \& Gredler, 2004; Coulson, 1975).

This paper discusses the important role of developing and evaluating a personal skills development (PSD) program as an integral part of business management education. It also suggests a strategy by which future evaluations might make a greater contribution to an understanding of important underlying relationships in the teaching-learning process. To illustrate both problems and approaches in evaluation, we conducted a study focusing on students' attitudes before and after the delivery of a PSD program in the business faculty of a medium size English-speaking university in Asia. Based on our findings, we propose that PSD programs have important issues 
that need be addressed more comprehensively than at present in the education literature if the pedagogical support of the current focus on PSD is to be fully realized.

\section{LITERATURE REVIEW OF PERSONAL DEVELOPMENT PROGRAMS}

\section{Personal Skills Development}

Personal skills development is considered to be very important for career success (Nabi \& Bagley, 1999). It is believed that developing a range of personal skills is essential for students prior to their leaving university and entering the work force, and that effective personal skills development depends on opportunities to practice skills with support and guidance that encourages and informs constructive reflection (Drummond, Nixon \& Wiltshire, 1998). However, Schaffer and Kelley (1993) indicated that there is increasing evidence that recent graduates of business schools do not possess the basic etiquette skills necessary to succeed in today's business world and that preparedness among college graduates is lacking. Nicolescu (2003), who carried out an empirical study in the business community, found that although employers look for recruits with knowledge, technical know-how and essential personal skills, higher education does not seem to be producing graduates with the required skills and abilities at the level organizations expect.

The literature review will focus on the recent changes in personal skills development, followed by a discussion on the fundamental components of PSD, and then delivery and evaluation of the development process.

\section{Recent changes in PSD}

In response to skill deficiencies, universities have launched educational reforms and have started to include personal skills modules in their curricula (e.g. Gammie et al., 2002; Nabi \& Bagley, 1999; Agyemang \& Unerman, 1998). Others provide assistance in these areas through extra-curricular activities (e.g. Raybould \& Sheedy, 2005). Some governments (e.g. the British government) encourage integrating higher education curricula and learning experiences associated with work, with a view to enabling students to become familiar with workplace practices (Saunders \& Machell, 2000). Their intention is to form more explicit and closer links between higher education, student experiences and employment practices. While effectively operationalizing an embedded development approach is difficult (Drummond et al., 1998), some researchers (e.g. Oliver \& Mcloughlin, 2001) claim that personal skills are best developed in meaningful contexts and through institutional approaches that are integrated into normal academic curricula.

The majority of universities now have institutional policies and directives that assert their commitment to personal skills development (Gilinsky \& Robison, 2008). The higher education sector has committed considerable resources, and will very likely continue to do so, to enhance approaches to PSD. Whether such a commitment is appropriate is no longer a meaningful question; whether resources are being used productively and effectively for such commitment certainly is (Drummond et al., 1998).

\section{Fundamental components of PSD}

Employers look for essential personal skills in graduates rather than merely subject-specific knowledge, and graduates need to provide evidence to employers that PSD activity has occurred during their education experience (Raybould \& Sheedy, 2005). The key issue is - what components of personal skills do employers want? With regard to the degree of importance, Hesketh (2000) found that communication, learning, problem solving and teamwork were rated by employers as the top four skills, with self-management being the fifth. Bennett (2002) surveyed 1,000 job advertisements targeting fresh graduates and found that communication, IT, organization, teamwork and interpersonal skills were deemed most important by recruiters. Crebert, Bates, Bell, Patrick and Cragnolini (2004) surveyed 664 graduates between 1997 and 2000 regarding the skills that students preferred should be developed in a university context. They found that verbal and written communication skills, critical analysis and evaluation, problem solving and teamwork skills were considered most important by students. A number of surveys to identify the skill requirements of employers suggest that communication, teamwork and interpersonal skills were highly in demand by employers (e.g. Harvey, 2000). 
Along this line of thinking, Pearse (2005) identified three fundamental attributes as cornerstones to business success: 'consideration', 'cooperation', and 'communication'. Consideration is the continuous and careful thought of developing a thoughtful and sympathetic opinion or plan. Attributes in this category include leadership, creativity and self-reflection. Cooperation is primarily about teamwork, and communication is the activity of conveying information effectively and efficiently (Pearse, 2005). Pearse's proposal is supported by studies which suggest that employers need skills in communication, co-operation and teamwork, as well as positive personal qualities such as the will to set and meet objectives and also to be innovative (e.g. Pearse, 2005; Harvey, 2000; Bradshaw, 1985).

\section{Delivery of PSD Programs}

Effective delivery of PSD is also deemed very important. The literature suggests that closer alignment with business learning and an integrative teaching approach that combines practical and classroom learning components is likely to produce the best results (e.g. Crebert et al., 2004; Hamilton, McFarland \& Mirchandani, 2000). Accordingly, workshops and seminars hosted by industry practitioners will need to be offered in addition to traditional class sessions delivered by academic staff. These sessions and workshops include presentations and discussions led by business professionals, experiential-based team exercises run by qualified facilitators, and portfolio system training hosted by system developers.

\section{Evaluation of PSD Programs}

There are many problems in evaluating education programs. They include a lack of proper planning, ineffective implementation, insufficient budget, and even courses that are conducted for the wrong reasons (Berge, 2008). Evaluating education programs is getting more and more difficult, because many academic departments are looking more for increased examination pass rates than for learning outcomes. In fact, many traditional methods of course evaluation seek feedback only on particular dimensions of teaching or courses, for instance, student attendance and pass rates (Mckenzie, Sheely \& Trigwell, 1998). Recently, educators have tended to take a slightly different approach by focusing more holistically, allowing students to express feelings about their own learning experience (Wankel, 2009; Gilinsky \& Robison, 2008). Student feedback can be a valuable source of information for course evaluation, not just in terms of what has happened but by how people feel about what has happened (Mckenzie et al, 1998). This information appears to be very useful for staff in the process of improving their courses and teaching.

We propose that the evaluation of PSD needs to be considered in the context of students' social environment. In other words, the evaluation of a student's learning outcomes must take into account that student's social construction of reality (Berger \& Luckmann, 1966). Reality as experienced by the student has an important additional value. This assumption also applies to a student's perception of their own learning experience. Research findings reveal that students' emotional feelings significantly influence their approaches to learning and studying (Mckenzie et al, 1998). In our study, we intended to take a deeper look into the response of students about the PSD program in question, and at the same time, assess the impact of the program on students before and after they had completed the program.

\section{DESIGNING AND IMPLEMENTING A PSD PROGRAM IN ASIA}

\section{An Evaluation Study in an Asian University}

To assess the effectiveness of the PSD program, we conducted in 2010 a design and evaluation study in a local tertiary education institution in Hong Kong that offers a variety of undergraduate and postgraduate skill-based programs. It is one of the few universities in Asia that use English as an official language in teaching, research and internal communication.

Hong Kong is the second largest international financial centre in Asia Pacific and is ranked amongst the top six financial centers in the world (Sassen, 1999; Jao, 1997). As such, Hong Kong is expected to have a workforce with the skills, competencies and productivity to successfully compete with its international counterparts. In the 
Education Reform Proposals for the education system in Hong Kong (Hong Kong Government Education Commission, 2000), directions were set for transforming the curriculum at the tertiary level so as to increase student participation and actual practices in the learning process.

\section{Developing a Skills development Program}

Since 2008, the Business Faculty of the University has developed a program for business students to enhance their personal skills. The program, entitled 'Personal Skills Development' (PSD), aims at broadening students' self-awareness of competencies required by the business world, and building and fostering improved personal skills of business students. Based on the framework proposed by Pearse (2005), the PSD program builds upon three important attributes: communication, cooperation, and consideration. Major topics covered in the PSD program include 'mastering the art of communication' and 'powerful business presentation series' (i.e. communication), 'working with others' (i.e. cooperation), and 'creativity secrets' and 'reflection of yourself' (i.e. consideration). Figure 1 shows the framework.

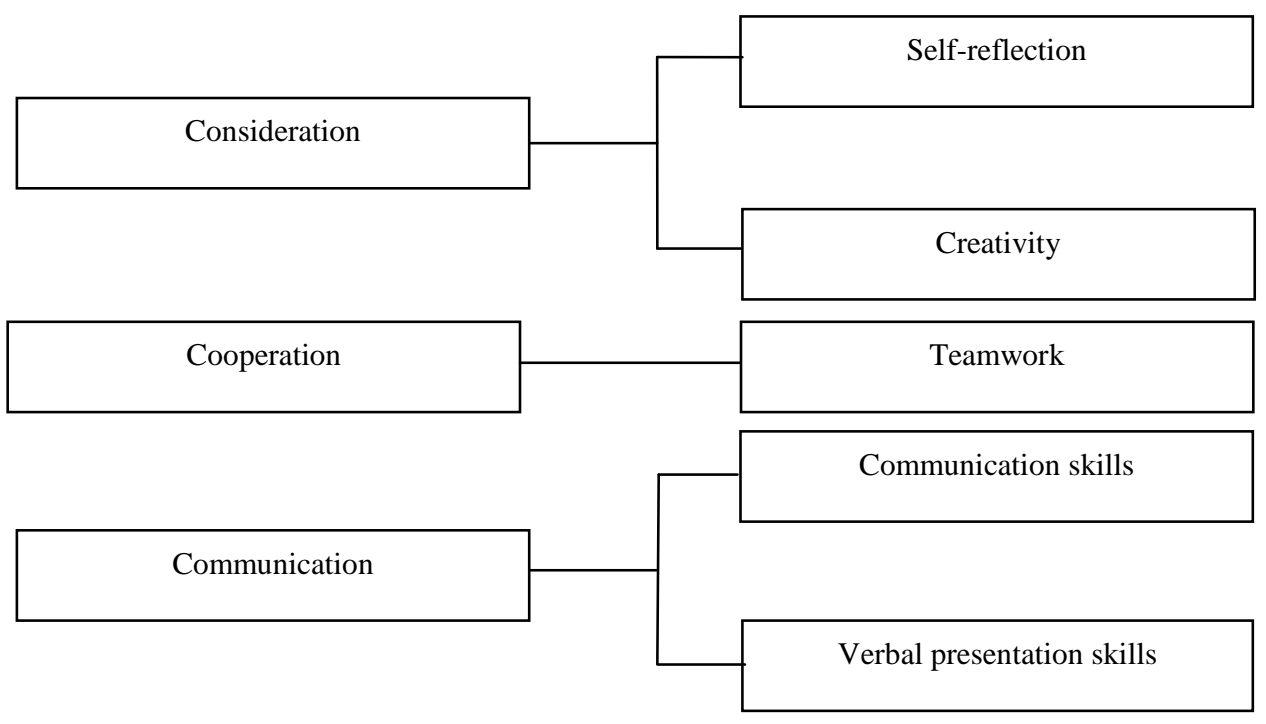

Pearse's 3C Model of PSD

5 major development objectives in the PSD program

Figure 1:

Framework of Personal Skills Development (PSD) Program

\section{Program Structure}

In the PSD program, various types of skills are developed through a combination of mini-lectures, discussion-reflection sessions, practices, and experiential exercises. The program is delivered within a 14-week semester of 42 contact hours and represents a typical undergraduate 3-credit subject. The class size of each workshop is about 18-22 students. The weekly workshop provides opportunities to develop five major personal skills, focusing on a designated discussion topic. The PSD teaching team includes faculty members, business professionals, qualified facilitators and system engineers.

The structure of the PSD program consists of the following four parts: 


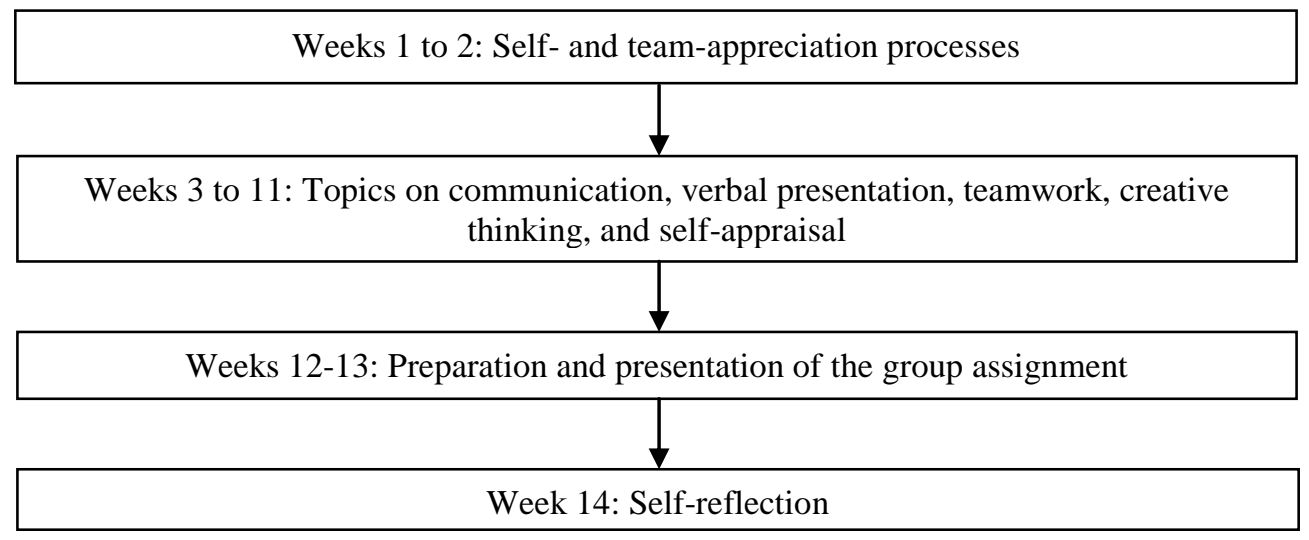

Figure 2:

Structure of Personal Skills Development (PSD) Program

Part 1 (Weeks 1 and 2) - Students are given an overview of the program learning objectives, structure, assignments and assessment. Lectures aim to make students aware of employers' demands for employees' personal skills. The concepts of journaling (recording thoughts and ideas) and developing business plans are introduced to help students prepare for individual and group assignments. The individual assignment requires students to produce a reflective essay to be submitted at the end of the semester. The contents during this part of the program also cover teamwork concepts and competencies to help prepare and create a trusting learning environment for both independent and team learning (Dineen, 2005). Students are randomly grouped into teams that will prepare the group assignment, for which each team produces and presents a business plan delineating a creative but feasible business idea.

Part 2 (Weeks 3 to 11) - Sessions cover the concepts of teamwork, communication, verbal presentations, creativity and self-appraisal skills. These sessions include group exercises, experiential based games and simulations, case studies, video show led by faculty members, discussions led by business professionals, experiential-based team activities run by qualified facilitators, and portfolio system training hosted by system engineers.

Part 3 (Weeks 12 and 13) - Groups present their business plans to their peers. Throughout the program (weeks 3-11), teams are required to verbally report the progress of their business plan and solicit feedback from the class.

Part 4 (Week 14) - Students deliver individual 5-minute presentations to the class and teaching faculty about their achievements and learning during the semester, with a view to shedding light on how they formulated an action plan for their continuous improvement. The information comes from students' personal reflections written in their journals on their learning experience, new perspectives, self-improvement commitments, and proposed action for continuous development.

\section{Experiential learning}

The design of the semester-long PSD program relies heavily on experiential learning theory (Kolb \& Kolb, 2005). The theory argues that learning is best conceived as a process instead of an outcome, and that engaging students in the learning process can improve learning in higher education and is considered the best way to enhance learning. Hence, learning is the process whereby knowledge is created through the transformation of experience. Accordingly, there are four stages in experiential learning theory: concrete experience, reflective observation, abstract conceptualization, and active experimentation. 
Each session of the PSD program above employed Kolb's four-stage model (Kolb \& Kolb, 2005). To begin, students were involved in a class exercise related to the topic of that particular lesson, designed to give them a 'concrete experience'. Second, groups of 4 to 5 students go through structured discussions that lead them to reflect on the learning experience and behaviors in the process. At this stage, questions directed them to look for behavior patterns, tendencies and inconsistencies, Kolb's 'reflection' phase. In a teacher-led debriefing session that drew out the learners' theoretical positions and generalization of principles, the stage of 'abstract conceptualization' took place. For the last stage of experiential learning theory ('active experimentation'), it is operationalized by adopting the suggestions from Gibbs (1988) and Hansen (2006). Gibbs (1988) suggests providing learners with substitute experiences to test the generalized laws in a new setting. Hansen (2006) stressed the importance of providing class time for team projects and argued that such an act leads to behavior development and team effectiveness. In-class team meetings are in place in the PSD classroom as the 'active experiential' stage requires students to apply their learning in a team setting.

\section{EVALUATION OF THE PSD PROGRAM}

\section{Research questions}

Students who went through the PSD program were given pre- and post-training surveys that asked them to evaluate the perceived skill improvement, effect of the training and satisfaction with the program. Personal skills are developed through the widespread use of cooperative/active learning teams; project and tutorial classes; a continuous improvement regime for verbal and written reporting; and specific training in teamwork, leadership, assertiveness and decision making. To assess the effectiveness of PSD on the set of specified skill areas, the following research questions are to be addressed:

1. Do students perceive that they have any improvement in the skill areas over the training period?

2. How do students rate the impact of the program on their skill development?

3. Are the students satisfied with the program?

Findings from this research will be of interest to universities considering graduates' attributes and employability, and will also offer educators insights to curriculum design, especially in enhancing PSD in their faculty.

\section{Methods and analysis}

The skill areas examined in the study were targeted to reflect the focus of the program. PSD was developed with an emphasis on five basic personal skills: communication, creativity, self-appraisal, teamwork and verbal presentations. The survey was designed to assess the perceived effect of PSD on the students related to these skill areas.

Two anonymous surveys were conducted to explore students' perceptions of the extent to which the program made a difference in ability improvement, whether the program had an impact on the students related to their skill development and their satisfaction with the program. Survey participants were undergraduate students studying the PSD program in the fall semester 2010-2011. The 157 students included in the survey population were business students from a variety of business majors, including accounting, logistics, marketing and general management. Some questionnaires were excluded from the analysis because of missing data, making the final sample size 145 .

A pre-course measure during the first week of the semester was administered to capture respondents' perceived ability levels in the five skills areas. During the last week of the semester, after the respondents had received the training, they were asked again to rate their ability levels in the same areas.

The change in the ability level of each of the five skill areas before and after participating in the PSD program was used to measure the extent of improvement (or deterioration). Pair $t$-tests were used to examine the statistical significance of students' perceived changes before and after the PSD program. Ability level was assessed 
using a 5 -item scale $(1=$ No extent; $5=$ Very large extent $)$ developed for this study. Two sample items were "My present ability level in communication skills," and "My present ability level in creativity skills".

As a counter check on the perceived ability levels, after the PSD program was over, another study was conducted to assess the perceived impact and personal evaluation of the PSD program itself. A 5-item measure to capture the perceived impact of the program on the ability of each skill was rated on a 5-point Likert scale $(1=$ Not at all; $5=$ Extremely positive). Respondents made a holistic evaluation of the training's positive impact on their skill development.

Specifically, program impact was assessed using a 5-item scale $(1=$ Strongly disagree $; 5=$ Strongly agree $)$ developed for this study. Two sample items were "This program has a positive impact on the development of communication skills," and "This program has a positive impact on the development of creativity skills".

Satisfaction with the program was measured by using seven items developed by Chen, Donahue and Klimoski (2004) with a 5-point Likert scale $(1=$ Strongly disagree; $5=$ Strongly agree $)$. One item was dropped from the original 8-item instrument because the language structure of that particular item seemed to be unclear to persons whose first language is not English.

The questionnaires were coded for anonymity, then distributed and administered by a research assistant with no teaching faculty present.

\section{Results}

Descriptive statistics and results of paired $t$-tests are given in Table 1 . The perceived ability levels on the two scales, before and after training, were compared. Information from the table shows that the students perceived a higher ability level by the end of the PSD program The before-after differences for perceived ability skill levels were positive and statistically significant $(p<.01)$, indicating that students were positive about improvement in their personal skills.

Table 1: Pre- and Post-Test Values: Descriptive Statistics and Results of Paired t-Test

Paired Samples Test

\begin{tabular}{|c|c|c|c|c|c|c|c|c|c|}
\hline & & \multicolumn{5}{|c|}{ Paired Differences } & \multirow[b]{3}{*}{$\mathrm{t}$} & \multirow[b]{3}{*}{$\mathrm{df}$} & \multirow[b]{3}{*}{ Sig. (2-tailed) } \\
\hline & & \multirow[b]{2}{*}{ Mean } & \multirow[b]{2}{*}{ Std. Deviation } & \multirow{2}{*}{ Std. Error Mean } & \multicolumn{2}{|c|}{$\begin{array}{c}95 \% \text { Confidence Interval } \\
\text { of the Difference }\end{array}$} & & & \\
\hline & & & & & Lower & Upper & & & \\
\hline Pair 1 & $\begin{array}{l}\text { Communication (before) - } \\
\text { Communication (after) }\end{array}$ & -.27 & .898 & .074 & -.42 & -.13 & -3.685 & 145 & .000 \\
\hline Pair 2 & $\begin{array}{l}\text { Creativity (before) - } \\
\text { Creativity (after) }\end{array}$ & -.59 & 1.112 & .092 & -.77 & -.41 & -6.400 & 145 & .000 \\
\hline Pair 3 & $\begin{array}{l}\text { Verbal presentations (before) } \\
\text { - Verbal presentations (after) }\end{array}$ & -.59 & 1.028 & .085 & -.76 & -.42 & -6.921 & 145 & .000 \\
\hline Pair 4 & $\begin{array}{l}\text { Self-appraisal (before) - } \\
\text { Self-appraisal (after) }\end{array}$ & -.31 & .843 & .070 & -.45 & -.17 & -4.416 & 145 & .000 \\
\hline Pair 5 & $\begin{array}{l}\text { Teamwork (before) - } \\
\text { Teamwork (after) }\end{array}$ & -.30 & .746 & .062 & -.42 & -.18 & -4.880 & 145 & .000 \\
\hline
\end{tabular}

On a Likert Scale of 1-5, with 1 being the lowest score, and 5 being the highest score.

Respondents were more inclined to agree that the program had a positive impact on the development of the skill areas set out by the program. Table 2 shows that scores for all five items were well above 3.0 (on a five-point scale). Communication and teamwork were the two most highly rated skills (3.69 and 3.78 respectively), while 
creativity had the lowest score (3.36). The implication of these results is that the PSD training is helpful in improving all five skills viewed as necessary for business. Participants were generally positive about the effectiveness of the program.

Table 2: Respondents' mean scores in relation to the impact of PSD on skill development

\begin{tabular}{|c|c|c|}
\hline Questions & $\begin{array}{c}\text { Mean score } \\
(n=145)\end{array}$ & SD \\
\hline 1. This program has a positive impact on the development of communication skills & 3.69 & .63 \\
\hline 2. This program has a positive impact on the development of creativity skills & 3.36 & .74 \\
\hline 3. This program has a positive impact on the development of self-appraisal & 3.60 & .84 \\
\hline 4. This program has a positive impact on the development of teamwork skills & 3.78 & .64 \\
\hline 5. This program has a positive impact on the development of verbal presentation skills & 3.64 & .71 \\
\hline
\end{tabular}

Table 3 shows the mean values for students' satisfaction with the program, which ranged from 4.13 to 4.42 on the 5-point scale. In particular, there was a very positive response toward the statements "taking this program was a positive experience" and "I am satisfied with what I've learnt in this program" (4.42 and 4.19 respectively). In general, respondents were quite satisfied with the PSD program.

Table 3: Respondents' mean scores and percentage of satisfaction with the program

\begin{tabular}{|c|c|c|}
\hline Questions & $\begin{array}{c}\text { Mean score } \\
(n=145)\end{array}$ & $\mathrm{SD}$ \\
\hline 1. I am satisfied with what I've learnt in this program & 4.19 & .55 \\
\hline 2. I really enjoyed taking this program & 4.22 & .65 \\
\hline 3. Taking this program was a good choice & 4.27 & .64 \\
\hline 4. I have learned useful skills in this program & 4.29 & .62 \\
\hline 5. I am really happy that I've taken this program & 4.18 & .68 \\
\hline 6. I would strongly recommend this program & 4.13 & .71 \\
\hline 7. Taking this program was a positive experience & 4.42 & .56 \\
\hline
\end{tabular}

The results support the notion that the PSD program embedded in the curriculum is an effective means of preparing business professionals for future career. The program has the potential of improving participants' abilities in all five skill areas.

\section{CONCLUSION AND DISCUSSION}

\section{Discussion}

The results of this study lends support to the a PSD program in that students were quite satisfied with the program, and most of them understood that it was designed to improve specific personal skills required by the business world. The survey data support the argument that a PSD program embedded in the business curriculum is an effective way to develop required skills amongst business students. A comparative test of pre- and post-program perceived ability suggests that the program was useful for the students. Respondents to the surveys also supported the idea that the program had a positive impact on their skill development, and they felt satisfied with the learning experience. Such positive feedback is consistent with previous studies investigating skills development (e.g. Agyemang \& Unerman, 1998; Butler, Johnson \& Forbes, 2008; Oliver \& Mcloughlin, 2001).

We believe that a number of factors contributed to the success of the PSD program. The program is a skilloriented experience focusing primarily on the demonstrative behaviors and attitudes demanded by business employers. The program objectives center on a relatively small set of professional skills: communication, creativity, 
self-appraisal, teamwork and verbal presentation. Specific sessions are devoted to develop well-defined set of skills using experience-based and highly interactive pedagogical techniques. As a result of such concentration, students are more engaged in in-depth learning, repeated practice, feedback and self-reflection.

The quality of the instructors is another factor contributing to the success of the program. It is critical that the instructor of a skills development program with a business focus have knowledge and skills acquired from practical experience in the field. Having instructors with a solid business grounding helps ensure that integrating knowledge and skills is based on the requirements of business practice. The program described above has brought together seasoned business practitioners and program-matter experts who are able to recount real life experiences to enrich the scope and practicality of the students' learning experience.

\section{Limitations}

The study has three major limitations. First, although this study sheds light on the process and evaluation of the PSD program for business students, the findings are based solely on a self-reported evaluation of effectiveness from the perspective of students. Further research can be undertaken to measure the effectiveness from a multidimensional perspective. Second, since the evaluation is merely done in a local university in Hong Kong, generalizing the study to other tertiary institutions is yet to be analyzed and tested. Third, we need more evidence to determine whether students will be able to apply personal skills effectively in the workplace after they graduate. Future research that focuses on the extent to which students use the skills they learn during their study in their careers would be very helpful.

\section{Practical implications and conclusion}

PSD is considered to be effective in improving the employability of business students. The program resulted in improved perceived ability and had a positive impact on skill development. The experience provides certain levels of assurance for business educators to enhance personal skills amongst students, and the design could be adopted as regular practice in undergraduate programs.

Practitioners, researchers and academics continue to criticize the inability of business programs to address real business and organizational issues. In light of this, considerable resources have been allocated to enhancing business-related knowledge, and skill-based modules are a feature of undergraduate programs in many universities (e.g. Hannah \& Venkatachary, 2010). However, taking on embedded approaches and incorporating skills development in higher education has received little attention in universities. This paper has outlined a personal skills development program embedded in the business curriculum to accommodate the delivery of skills to undergraduate business students. Findings from the study suggest that behavioral learning centered on developing the required skills is not only necessary in higher education but is also well received by students.

\section{AUTHOR INFORMATION}

Dr Elvy Pang is a Lecturer at the Department of Management and Marketing of the Hong Kong Polytechnic University. Her main research interests are in understanding the characteristics and dynamics associated with team and individual effectiveness in the Higher Education context. She is also interested in adult creativity and in particular, how creativity through collective efforts builds individual competitive advantage. E-mail: elvy.pang@polyu.edu.hk. Corresponding author.

Dr Humphry Hung has more than 20 years' practical experience in training and development. He is currently lecturing at the Department of Management and Marketing of the Hong Kong Polytechnic University. He has published in several international refereed journals and conference proceedings. He is also a regular contributor to business and management training and education columns in local newspapers. 


\section{REFERENCES}

1. Agyemang, G. \& Unerman, J. (1998). Personal skills development and first year undergraduate accounting education: a teaching note, Accounting Education, 7(1), 87-92.

2. Bennett, R. (2002). Employers' Demands for Personal Transferable Skills in Graduates: a content analysis of 1000 job advertisements and an associated empirical study, Journal of Vocational Education and Training, 54(4), 457-475.

3. Bennis, W.G. \& O'Toole, J. (2005). How Business Schools Lost their Way, Harvard Business Review, 83(5), 96-104.

4. Berge, Z. L. (2008) Why it is so hard to evaluate training in the workplace, Industrial and Commercial Training, 40(7), $390-39$.

5. Berger, P. L. \& Luckmann, T. (1966) The Social Construction of Reality: A Treatise in the Sociology of Knowledge, Garden City, NY: Anchor Books.

6. Bradshaw, D. (1985). Transferable Intellectual and Personal Skills, Oxford Review of Education, 11(2), 201-216.

7. Butler, D., Johnson, L. \& Forbes, B. (2008). An Examination of a Skills-Based Leadership Coaching Course in an MBA Program, Journal of Education for Business, 83(4), 227-232.

8. Chen, G., Donahue, L.M. \& Klimoski, R.J. (2004). Training Undergraduates to Work in Organizational Teams, Academy of Management Learning \& Education, 3(1), 27-40.

9. Coulson, J. E. (1975). Problems and Approaches in Education Program Evaluation. Paper presented at the $60^{\text {th }}$ Annual Meeting of the American Educational Research Association, San Francisco, California, April 19-23, 1975.

10. Crebert, G., Bates, M., Bell, B., Patrick, C. \& Cragnolini, V. (2004). Developing generic skills at university, during work placement and in employment: graduates' perceptions, Higher Education Research \& Development, 23(2), 147-165.

11. Dineen, B. R. (2005). TeamXchange: A team project experience involving virtual teams and fluid team membership. Journal of Management Education, 29, 593-616.

12. Drummond, I., Nixon, I. \& Wiltshire, J. (1998). Personal transferable skills in higher education: the problems of implementing good practice, Quality Assurance in Education, 6(1), 19-27.

13. Flannery, B. L., \& Pragman, C. H. (2010). Service-learning and integrated course redesign: Principles of management and the campus kitchen metaproject. Journal of Management Education, 34, 11-38.

14. Gammie, B., Gammie, E. \& Cargill, E. (2002). Personal skills development in the accounting curriculum, Accounting Education, 11(1), 63-78.

15. Garavalia, L. \& Gredler, M. (2004). Teaching Evaluation through Modeling: Using the Delphi Technique to Assess Problems in Academic Programs, American Journal of Evaluation, 25(3), 375-380.

16. Gilinsky, A., \& Robison, R. (2008). A proposed design for the business capstone course with emphasis on improving students' information competency. Journal of Management Education, 32, 400-419.

17. Gibbs, G. (1988). Learning by doing: A guide to teaching and learning methods, London: Further Education Unit.

18. Hamilton, D., McFarland, D. \& Mirchandani, D. (2000). A decision model for integration across the business curriculum in the 21st century, Journal of Management Education, 24 (1), 102-121.

19. Hannah, D. R., \& Venkatachary, R. (2010). Putting "organizations" into an "organization theory" course: A hybrid CAO model for teaching organization theory, Journal of Management Education, 34, 200-223.

20. Hansen, R. S. (2006). Benefits and problems with student teams: Suggestions for improving team projects, Journal of Education for Business, 82(1), 11-19.

21. Harvey, L. (2000). "New Realities: The Relationship between Higher Education and Employment", Tertiary Education and Management, 6(1), 3-8.

22. Hesketh, A.J. (2000). Recruiting an Elite? Employers' perceptions of graduate education and training, Journal of Education \& Work, 13(3), 245-271.

23. Hong Kong Government Education Commission. (2000). Review of education system: Reform proposals, Hong Kong Government, Hong Kong.

24. Jao, Y.C. (1997). Hong Kong international financial centre: Evaluation, prospects and policies, City University of Hong Kong Press, Hong Kong. 
25. Kolb, A. Y., \& Kolb, D. A. (2005). Learning styles and learning spaces: Enhancing experiential learning in higher education. Academy of Management Learning \& Education, 4(2), 193-212.

26. Mckenzie, J., Sheely, S., Trigwell, K. (1998). Drawing on Experience: a holistic approach to student evaluation of courses, Assessment \& Evaluation in Higher Education, 23(2), 153-164.

27. Nabi, G. R., \& Bagley, D., (1999). Graduates' perceptions of transferable personal skills and future career preparation in the UK, Education \& Training, 41(4), 184-193.

28. Nicolescu, L. (2003), Higher Education in Romania: Evolution and Views from the Business Community, Tertiary Education and Management, 9(1), 77-85.

29. Oliver, R. \& Mcloughlin, C. (2001), Exploring the Practice and Development of Generic Skills through Web-Based Learning, Journal of Educational Multimedia and Hypermedia, 10(3), 207-225.

30. Pearse, J. R. (2005). Teaching the 3 Co's. 2005 ASEE Annual Conference and Exposition, Portland, Oregon.

31. Raybould, J. \& Sheedy, V. (2005). Are graduates equipped with the right skills in the employability stakes?, Industrial and Commercial Training, 37(4/5), 259-63.

32. Sassen, S. 1999, Global Financial Centers, Foreign Affairs, 78(1), 75-87.

33. Saunders, M. \& Machell, J. (2000). Understanding emerging trends in higher education curricula and work connections, Higher Education Policy, 13(3), 287-302.

34. Schaffer \& Kelley (1993). Education in Business Etiquette: Attitudes of Marketing Professionals, Journal of Education for Business, 68(6), 330-33.

35. Wankel, C. (2009). Management education using social media. Organization Management Journal, 6, 251262. 
NOTES 